\title{
Response to the letter to editor: need for upper urinary tract stenting in cases of ureteral orifice injury during laser enucleation of the prostate
}

\author{
Dmitry Enikeev ${ }^{1}$
}

Received: 10 December 2018 / Accepted: 26 December 2018 / Published online: 12 April 2019

C) Springer Nature B.V. 2019

\section{Editor,}

Allow me to thank you for your reply to the article [1]. Your data look impressive, indeed. It is even better than the published results that I am aware of. For example, professor Kuntz reported four cases of ureteral orifice injury of 384 patients putting the rate of this complication at $1.0 \%$ [2].

This discrepancy may potentially be explained by the fact that scientific articles rely on data obtained from patients who are included in the study green-lit by the ethical committee. We have performed over 1500 surgeries and have only had seven instances of orifice injury. However, we can only officially report on 465 patients who gave informed consent and went through all stages of follow-up. Obviously, we provide data that meet all the accepted standards. But I have to note that neither complication rates nor the conventional enucleation technique was the focus of the article. Instead, we tried to suggest possible strategies to handle complications when they do occur and explore different approaches used by surgeons in cases of ureteral orifice injury. In our opinion, forgoing stenting during laser enucleation decreases the risks of infection, shortens surgery and facilitates rehabilitation. It also promises more comfort for the patient as there is no need for another cystoscopy to remove the stent.

We considered it important to share our experience because the topic of complications is not well explored yet. In a certain sense, this is "terra incognita". The fact that we are all humans may be partly to blame. We are more likely to gladly show our achievements than talk about difficulties or failures. However, every surgeon faces complications and it is their analysis that pushes us to deepen our knowledge and select the correct option when something goes awry. We find it essential to exchange our experiences as members of the community as it is the key to mutual professional growth. I would like to thank you once again for inviting a discussion.

Acknowledgements All authors state that they have no commercial interests in this paper.

\section{Compliance with ethical standards}

Conflict of interest No potential conflict of interest was reported by the authors.

Disclosure All authors state that they have no disclosure that might potentially bias they work.

Ethical approval For this type of study, formal consent is not required.

\section{References}

1. Enikeev D, Glybochko P, Rapoport L, Snurnitsyna O, Potoldykova N, Novoselova T, Laukhtina E, Taratkin M, Margulis V (2018) Need for upper urinary tract stenting in cases of ureteral orifice injury during laser enucleation of the prostate. Int Urol Nephrol. https://doi.org/10.1007/s11255-018-2007-6

2. Kuntz RM, Lehrich K, Ahyai S (2004) Does perioperative outcome of transurethral holmium laser enucleation of the prostate depend on prostate size? J Endourol 18(2):183-188

Publisher's Note Springer Nature remains neutral with regard to jurisdictional claims in published maps and institutional affiliations.

Dmitry Enikeev

dvenikeev@gmail.com

1 Institute for Urology and Reproductive Health, Sechenov

University, Bolshaya Pirogovskaya St, 2-1, Moscow,

Russia 119991 